Jurnal Media Agribisnis Vol. 3 No. 1 Tahun 2018 Hal 21 - 29

Media Komunikasi Hasil Penelitian Bidang Ilmu Agribisnis ISSN print 2587-7027

ISSN online 2541-6898

\title{
PERBANDINGAN ASPEK EKONOMI USAHATANI PADI SAWAH SISTEM JAJAR LEGOWO DAN SISTEM TEGEL DI DESA PUDAK KECAMATAN KUMPEH ULU KABUPATEN MUARO JAMBI
}

\author{
Ir. Nida Kemala MP ${ }^{1)}$ dan Bayu Pratama ${ }^{2)}$ \\ ${ }^{1)}$ Program Studi Agribisnis, Fakultas Pertanian Universitas Batanghari \\ ${ }^{2)}$ Alumni Program Studi Agribisnis, Fakultas Pertanian Universitas Batanghari \\ Jl. Slamet Riyadi-Broni, Jambi. 36122. Telp. +6274160103 \\ ${ }^{1)}$ email korespondesi : nidakemala@yahoo.com
}

\begin{abstract}
This study was conducted in Pudak Village, Kumpeh Ulu District, Muaro Jambi Regency. The research focused on an economic corner included farmer income, $R / C$ ratio and the difference of both farmer income and $R / C$ ratio between "Jajar Legowo" and "Tegel" cultivation system. Total population were 424 so the number of sample was 64 farmers (15\%), and was taken by proportional random sampling methode. While the method of research analysis was used description analysis. The prospect of this research aimed to supply a substance and information tobe use for both to do the further research or decision making. The result showed that the farmer income average of the farmer that applied "Jajar Legowo" cultivation system was Rp 13.477.962/Ha/Period, while those farmer that used "Tegel" cultivation system showed Rp 6.711.465/Ha/Period. R/C Ratio for both system were 2,23 and 1,79 respectively. This ratio showed that both system were reasonable to be continued. There showed a significanttly difference on both farmer income and $R / C$ ratio between the two different cultivation system ("Jajar Legowo" and "Tegel" cultivation system)
\end{abstract}

Keywords : paddy, income, $R / C$ ratio

\begin{abstract}
Abstrak
Penelitian ini dilakukan di Desa Pudak, Kecamatan Kumpeh Ulu, Kabupaten Muaro Jambi. Penelitian ini difokuskan pada Kajian kondisi ekonomi petani (pendapatan dan $\mathrm{R} / \mathrm{C}$ rasio) dalam usahatani tanaman padi dengan sistem jajar legowo dan sistem tegel. Jumlah populasi sebanyak 424 RTP maka jumlah sampel sebanyak 64 RTP yang ditentukan dengan metode "proporsional random sampling". Sedangkan metode analisis gunakan analisis deskriptif. Prospek penelitian ini adalah untuk memberikan bahan dan sumber informasi bagi pihak yang berkepentingan baik untuk melakukan penelitian lebih lanjut maupun untuk dasar pengambilan kebijakan. Hasil penelitian menunjukkan bahwa rata-rata pendapatan yang diperoleh petani sampel dari usahatani padi dengan sistem jajar legowo sebesar Rp 13.477.962/Ha/MT. Sedangkan Rata-rata pendapatan yang diperoleh petani sampel dari usahatani padi sawah yang menggunakan sistem tanam tegel sebesar Rp 6.711.465/Ha/MT. R/C Ratio untuk usahatani padi sawah yang menggunakan sistem jajar legowo dengan tegel adalah 2,23 dan 1,79. Artinya usahatani padi sawah yang menggunakan sistem tanam jajar legowo maupun sistem tegel sama-sama menguntungkan dan layak. Terdapat perbedaan yang nyata pada
\end{abstract}

Diterbitkan oleh Program Studi Agribisnis Fakultas Pertanian Universitas Batanghari Jambi

Halaman 21 
Jurnal Media Agribisnis Vol. 3 No. 1 Tahun 2018 Hal 21 - 29

Media Komunikasi Hasil Penelitian Bidang Ilmu Agribisnis

ISSN print 2587-7027

ISSN online 2541-6898

pendapatan dan $\mathrm{R} / \mathrm{C}$ ratio usahatani padi dengan sistem jajar legowo dan sistem tegel di Desa Pudak, Kecamatan Kumpeh Ulu, Kabupaten Muaro Jambi.

Kata kunci : padi, pendapatan, $\mathrm{R} / \mathrm{C}$ ratio

\section{PENDAHULUAN}

Sektor pertanian dalam pembangunan nasional berperan penting, karena selain menyediakan pangan bagi seluruh penduduk juga merupakan sektor andalan penyumbang devisa negara dari sektor non migas. Pembangunan pertanian tanaman pangan khususnya padi terfokus pada peningkatan produksi yang harus diikuti dengan pengembangan usahatani berbasis agribisnis agar dapat meningkatkan pendapatan petani. Laju peningkatan produktivitas padi sawah di Indonesia cenderung melandai sehingga diindikasikan bahwa sistem intensifikasi padi sawah belum mampu meningkatkan produksi dan produktivitas. Kontribusi sektor pertanian terhadap PDRB Provinsi Jambi tahun 2015 adalah sebesar 28,25\%. Sedangkan untuk subsektor tanaman pangan sendiri kontribusinya sebesar 5,99\%. Saat ini pemerintah berupaya meningkatkan pemanfaatan lahan pencetakan sawah baru. Hal ini dilakukan agar ketahan pangan semakin kuat, terutama di Provinsi Jambi (Dinas Ketahanan Pangan Provinsi Jambi.2015).

Jambi merupakan salah satu provinsi yang ikut membantu menyediakan kebutuhan beras di Provinsi Jambi. Dalam hal ini khususnya Kabupaten Muaro Jambi memiliki luas tanam $6.698 \mathrm{Ha}$ dengan produksi 26.614 Ton dan menunjukkan produktivitas terkecil dibandingkan denga kaupaten lain di Provinsi Jambi yaitu sebesar 3,973 Ton/Ha. Sedangkan salah satu kecamatan di Kabupaten Muaro Jambi yang berpotensi dalam produksi padi adalah Kecamatan Kumpeh Ulu yang memiliki produktivitas padi no 2 tertinggi setelah Keamatan Sekernan (4,32 Ton/Ha) yaitu sebesar 3,97 Ton/Ha, dengan jumlah produksi cukup tinggi yaitu sebesar 4.216 ton serta luas tanam sebesar 1.061 hektar pada tahun 2015. (Dinas Pertanian Kabupaten Muaro Jambi, 2016). Sebagian besar masyarakat penduduk di Kecamatan Kumpeh Ulu adalah petani padi. Dalam hal ini Desa Pudak merupakan desa di Kecamatan Kumpeh Ulu yang memiliki produktivitas padi terbesar yaitu 4,42 Ton/Ha, dengan produksi 1.441 ton dengan luas lahan $341 \mathrm{Ha}$. Hal ini dapat menunjukan bahwa tanaman padi di Desa Pudak mampu tumbuh dengan baik karena sesuai dengan luas tanam dan Desa Pudak merupakan sentra penghasil gabah padi tebesar di antara desa lain yang ada di Kecamatan Kumpeh Ulu.(BP3K Desa Arang-Arang, 2016)

Usahatani padi sawah disamping sebagai penyedia makana pokok untuk di konsumsi, juga bisa sebagai sumber pendapatan perlu diketahui sistem penanaman yang memberikan keuntungan ekonomi yang optimal, dalam hal ini berkaitan dengan sistem penanaman sehingga perlu membandingkan dua sistem penanaman yang berbeda. Maka dari itu untuk melihat seberapa besar pendapatan dan kelayakan usahatani padi sawah dari kedua sistem tersebut maka penulis tertarik untuk melakukan penelitian dengan judul " Perbandingan Aspek Ekonomi Usahatani Padi Sawah (Oriza sativa L) Sistem Tanam Jajar Legowo Dengan Sistem Tegel di Desa Pudak Kecamatan Kumpeh Ulu Kabupaten Muaro Jambi “ Dalam berusahatani padi tentu mengharapkan pendapatan yang sesuai dengan harapan, sehingga berkembanglah beberapa sistem penanaman yang 
Jurnal Media Agribisnis Vol. 3 No. 1 Tahun 2018 Hal 21 - 29

Media Komunikasi Hasil Penelitian Bidang Ilmu Agribisnis

ISSN print 2587-7027

ISSN online 2541-6898

diharapkan dapat memberikan dampak yang positif terhadap pendapatan petani. Terdapat dua sistem penanaman padi di lokasi penelitian yaitu sistem tanam "jajar legowo" dengan "sistem tegel" yang menunjukkan adanya perbedaan dalam teknik menanam sehingga diprediksi menimbulkan perbedaan pembiayaan dan hasil produksi sehingga berujung pada pendapatan yang juga mungkin berbeda. Berdasarkan uraian tersebut, maka perlu adanya kajian menyangkut : besar pendapatan dan $\mathrm{RC}$ ratio yang diperoleh petani dan perbedaan pendapatan dan $\mathrm{RC}$ ratio usahatani padi sawah pada dua sistem tanam yang berbeda yaitu jajar legowo dengan sistem tegel. Diharapkan hasil penelitian ini menjadi bahan dan sumber informasi bagi pihak yang berkepentinngan baik untuk melakukan penelitian lebih lanjut maupun untuk dasar pengambilan kebijakan.

\section{METODOLOGI PENELITIAN}

Penelitian dilakukan di Desa Pudak, Kecamatan Kumpeh Ulu, Kabupaten Muaro Jambi dengan pertimbangan bahwa desa ini merupakan salah satu sentra penghasil produksi tanaman padi sawah dimana wilayah ini memiliki produktivitas padi tertinggi (4,42 Ton/ Ha) di antara desa lainnya di Kecamatan Kumpeh Ulu. Kajian penelitian difokuskan untuk mempelajari kondisi ekonomi petani usahatani tanaman padi sawah sistem jajar legowo dengan sistem tegel.

Penelitian ini menggunakan metode survey dan data yang dikumpulkan bersumber data data primer dan sekunder. Data primer diperoleh dari petani sampel melalui wawancara dengan menggunakan daftar kuisioner yang telah disiapkan sesuai dengan tujuan penelitian. Sedangkan data sekunder diperoleh dari dinas atau instansiinstansi terkait yang berhubungan dengan penelitian.

Sampel diambil secara proporsional random sampling dengan jumlah sampel sebanyak 64 RTP atau sebesar $15 \%$ dari total populasi yang berusahatani padi sawah adalah sebanyak 424 RTP. Hal ini sejalan dengan pendapat Winarno, (1994), yang menyatakan bahwa bila populasi cukup homogen, terhadap populasi di bawah 100 dapat digunakan sampel sebesar 50\% dan bila populasi di atas 100 maka besarnya sampel diambil 15\%. dan juga sampel manusia hendaknya di atas 30 orang besarnya. Karena populasi terdiri dari dua kelompok (kelompok petani dengan dua sistem budidaya yang berbeda yaitu sistem tanam jajar legowo dengan sistem tegel) maka pengambilan sampel diambil secara proposional random sampling dari masing-masing populasi dengan menggunakan rumus (Nazir, 1988) sebagai berikut :

$$
\begin{array}{ll}
n i=\frac{N i}{N} n & \text { Dimana: } \\
& \mathrm{ni} \quad=\text { Jumlah total sub sampel RTP. } \\
\mathrm{Ni} & =\text { Jumlah total sub populasi RTP. } \\
\mathrm{n} & =\text { Jumlah total sampel RTP. } \\
\mathrm{N} & =\text { Jumlah total populasi RTP. }
\end{array}
$$

Untuk mengetahui jumlah RTP sampel pada masing-masing usahatani padi pada sistem jajar legowo dengan tegel dapat dilihat pada Tabel 1. 
Jurnal Media Agribisnis Vol. 3 No. 1 Tahun 2018 Hal 21 - 29

Media Komunikasi Hasil Penelitian Bidang Ilmu Agribisnis

ISSN print 2587-7027

ISSN online 2541-6898

\begin{tabular}{llcc}
\hline \hline \multicolumn{4}{l}{ Tabel 1. Jumlah populasi dan sampel penelitian } \\
\hline No & Sistem tanam & $\begin{array}{c}\text { Jumlah sub populasi } \\
\text { (RTP) }\end{array}$ & $\begin{array}{c}\text { Jumlah sampel } \\
\text { (RTP) }\end{array}$ \\
\hline 1 & Jajar Legowo & 318 & 48 \\
2 & Tegel & 106 & 16 \\
\hline & Jumlah & 424 & 64 \\
\hline
\end{tabular}

Data yang diperoleh dari hasil penelitian dianalisi secara deskriptif baik kualitatif maupun kuantitatif. Biaya produksi diketahui dengan menjumlakan total biaya tetap dengan total biaya tidak tetap, sesuai dengan rumus sebagai berikut (Sudarman dan Algifari, 2001):

$$
\begin{array}{ll}
\mathrm{TC}=\mathrm{TFC}+\mathrm{TVC} & \text { Keterangan }: \\
& \mathrm{TC}=\text { Total Cost }(\mathrm{Rp} / \mathrm{Ha} / \mathrm{MT}) \\
& \mathrm{TFC}=\text { Total Fixed Cost }(\mathrm{Rp} / \mathrm{Ha} / \mathrm{MT}) \\
& \mathrm{TVC}=\text { Total Variabel Cost }(\mathrm{Rp} / \mathrm{Ha} / \mathrm{MT})
\end{array}
$$

Untuk menghitung besarnya biaya penyusutan dapat digunakan rumus Metode Garis Lurus (Sudarman dan Algifari, 2001):

$$
\begin{aligned}
& \mathrm{D}=\frac{\Gamma \mathrm{S}}{\mathrm{N}} \quad \begin{array}{ll}
\text { Keteranagan: } \\
\mathrm{D} \quad \text { Depreciation }(\mathrm{Rp} / \mathrm{MT})
\end{array} \\
& \mathrm{P} \quad=\text { Harga awal alat (Rp) } \\
& \mathrm{S}=\text { Harga akhir alat (dengan asumsi Rp 0) } \\
& \mathrm{N} \quad=\text { Perkiraan umur ekonomis (MT) }
\end{aligned}
$$

Untuk menghitung besarnya penerimaan ditentukan dengan menggunakan rumus Samuelson dan Nordhaus (2003) sebagai berikut:

$\mathrm{TR}=\mathrm{Pq} \cdot \mathrm{Q} \quad$ Keterangan:

$$
\begin{array}{ll}
\mathrm{TR} & =\text { Total Revenue }(\mathrm{Rp} / \mathrm{Ha} / \mathrm{MT}) \\
\mathrm{Pq} & =\text { Product Price }(\mathrm{Rp} / \mathrm{Kg}) \\
\mathrm{Q} & =\text { Quantity of Product }(\mathrm{Kg} / \mathrm{Ha} / \mathrm{MT})
\end{array}
$$

Untuk mengetahui pendapatan yang diperoleh digunakan rumus Boediono (1992) sebagai berikut:

$$
\begin{aligned}
& \mathrm{I}=\mathrm{TR}-\mathrm{TC} \quad \text { Keterangan: } \\
& \text { I }=\text { Income }(\mathrm{Rp} / \mathrm{Ha} / \mathrm{MT}) \\
& \mathrm{TR}=\text { Total Revenue }(\mathrm{Rp} / \mathrm{Ha} / \mathrm{MT}) \\
& \mathrm{TC}=\text { Total Cost }(\mathrm{Rp} / \mathrm{Ha} / \mathrm{MT})
\end{aligned}
$$

Menurut Fauzan. R. dalam Faliatra (2000), perhitungan untuk menentukan keberhasilan suatu usaha dapat dilakukan perhitungan dengan rumus:

$$
\begin{array}{ll}
\text { RC } \text { Ratio }=\frac{G I}{T C} & \text { Keterangan: } \\
& \text { GI }=\text { Gross Income (Rp/MT) } \\
& \text { TC }=\text { Total Cost }(\mathrm{Rp} / \mathrm{MT})
\end{array}
$$


Jurnal Media Agribisnis Vol. 3 No. 1 Tahun 2018 Hal 21 - 29

Media Komunikasi Hasil Penelitian Bidang Ilmu Agribisnis

ISSN print 2587-7027

ISSN online 2541-6898

Kriteria yang berlaku:

- $R C$ Ratio $>1$, artinya usaha layak untuk dilaksanakan.

- $R C$ Ratio $<1$, artinya usaha tidak layak untuk dilaksanakan.

- $R C$ Ratio $=1$, artinya usaha tidak untung maupun rugi.

Analisis yang digunakan untuk melihat perbedaan tingkat pendapatan dan $\mathrm{R} / \mathrm{C}$ ratio digunakan uji dua rara-rata, untuk sampel independen dengan jumlah sampel yang berbeda menurut (Djarwanto dan Pangestu Subagyo,1993). Dengan formulasi sebagai berikut :

$$
\begin{aligned}
& \mathrm{Z}=\frac{\left(\mathrm{X}_{1}-\mathrm{X}_{2}\right)}{\sqrt{\left(\mathrm{S}_{1}^{2} / \mathrm{n}_{1}+\mathrm{S}_{2}^{2} / \mathrm{n}_{2}\right)}} \\
& \text { Dimana : } \\
& n_{1}=\text { Jumlah sampel sistem jajar legowo } \\
& n_{2}=\text { Jumlah sampel sistem tegel } \\
& \mathrm{S}_{\mathrm{i}}^{2}=\frac{\sum \mathrm{X}_{\mathrm{i}}^{2}-\left(\sum \mathrm{X}_{\mathrm{i}}\right)^{2} / \mathrm{n}_{\mathrm{i}}}{\mathrm{n}_{\mathrm{i}}} \\
& \mathrm{X}_{1}=\text { Rata-rata pendapatan sistem jajar legowo } \\
& \mathrm{X}_{2}=\text { Rata-rata pendapatan sistem tegel } \\
& \mathrm{S}_{\mathrm{i}}{ }^{2}=\text { Varian sampel masing-masing sistem }
\end{aligned}
$$

Hipotesis: $\mathrm{H}_{0}: \mu_{1=} \mu_{2}$ (Tidak ada perbedaan baik pendapatan maupun $\mathrm{R} / \mathrm{C}$ rasio antara sistem jajar legowo dengan sistem tegel).

$\mathrm{H}_{\mathrm{a}}: \mu_{1 \neq} \mu_{2}$ (ada perbedaan baik pendapatan maupun $\mathrm{R} / \mathrm{C}$ rasio antara sistem jajar legowo dengan sistem tegel).

Kaidah keputusan $(\alpha=5 \%)$ :

$$
\begin{aligned}
& \mathrm{H}_{0} \text { ditolak.bila } Z_{\text {hitung }} z_{\text {tabel }} \\
& \mathrm{H}_{0} \text { diterima bila } z_{\text {hitung }} z_{\text {tabel }}
\end{aligned}
$$

\section{Konsepsi Pengukuran Variabel}

1. Petani sampel yaitu petani padi yang melakukan usahatani padi pada sistem jajar legowo dan sistem tegel di Desa Pudak Kecamatan Kumpe Ulu Kabupaten Muaro Jambi.

2. Total Biaya adalah semua biaya yang digunakan dalam proses produksi usahatani padi sawah yang terdiri dari total biaya tetap dan total biaya tidak tetap (Rp/Ha/MT).

3. Biaya tetap adalah biaya yang penggunaaan sarananya tidak habis dalam satu masa tanam dan besar kecilnya tidak berkaitan dengan besar kecilnya hasil produksi dimana menghitung besarnya menggunakan nilai penyusutan (Rp/Ha/MT).

4. Biaya tidak tetap adalah biaya yang penggunaan sarananya habis dalam satu musim tanam dan besar kecilnya beraitan dengan besar kecilnya hasil produksi $(\mathrm{Rp} / \mathrm{Ha} / \mathrm{MT})$.

5. Hasil produksi adalah jumlah padi yang dihasilkan dari usahatani pada ke dua sistem $(\mathrm{Kg} / \mathrm{Ha} / \mathrm{MT})$.

6. Penerimaan adalah nilai hasil produksi yang merupakan hasil perkalian antara jumlah produk dan harganya (Rp/Ha/MT).

11. Pendapatan adalah selisih penerimaan dengan total biaya produksi $(\mathrm{Rp} / \mathrm{Ha} / \mathrm{MT})$.

12. Gross Income adalah penerimaan usahatani padi (Rp/Ha/MT). 
Jurnal Media Agribisnis Vol. 3 No. 1 Tahun 2018 Hal 21 - 29

Media Komunikasi Hasil Penelitian Bidang Ilmu Agribisnis

ISSN print 2587-7027

ISSN online 2541-6898

\section{Identitas Petani}

HASIL DAN PEMBAHASAN

Rata-rata umur petani dengan sistem jajar legowo adalah 50 tahun.Umur petani sampel berkisar 40-75 tahun. Mayoritas terletak pada selang 40-45 tahun yaitu sebanyak 17 RTP $(35,41 \%)$, dan minoritas petani terletak pada selang 70-75 tahun yaitu 1 RTP (2,08\%). Sedangkan umur petani dengan sistem tanam tegel berkisar 40-75 tahun dimana mayoritanya terletak pada selang umur 40-48 tahun yaitu sebanyak 9 RTP (56,25\%), dan minoritas terletak pada selang umur $67-75$ tahun sebanyak 1 RTP $(6,25 \%)$.

Pendidikan adalah hal yang sangat penting dalam kehidupan sebagai dasar memperoleh pengetahuan dan keterampilan.Tingkat pendidikan petani dengan sistem jajar legowo bervariasi dari SD sampai SLTA. Mayoritas baik petani dengan menggunakan sistem jajar legowo dan tegel adalah SD, yaitu masing-masing sebanyak 26 dan 8 RTP. Rendahnya tingkat pendidikan petani akan berpengaruh terhadap perencanaan dalam pengelolaan usahataninya, hal ini akan mempengaruhi tingkat produksi yang dihasilkan petani tersebut. Soeharjo dan Patong (1993), menyatakan bahwa semakin tinggi pendidikan petani maka kemampuan petani untuk meningkatkan pengelolaan usahataninya akan lebih baik baik terutama dari segi teknologi baru, pemahaman bercocok tanam dan pemasaran.

Jumlah tanggungan keluarga merupakan salah satu faktor yang mempengaruhi keberhasilan berusahatani, semakin banyak jumlah tanggungan keluarga maka semakin banyak kebutuhan yang akan dipenuhi oleh petani. Tanggungan keluarga terdiri dari istri, anak serta anggota keluarga lainnya yang tinggal bersama dalam keluarga sekaligus menjadi tanggung jawab kepala keluarga. Jumlah tanggungan keluarga petani terbanyak pada kedua sistem tanam adalah 3 orang (15 RTP pada sistem jajar legowo dan 6 RTP pada sistem tegel). Sedangkan jumlah tanggungan terkecil adalah 1 orang pada sistem jajar legowo (2 RTP) dan 2 orang pada sistem tegel (2 RTP). Sedangkan rata-rata jumlah tanggungan keluarga petani sampel yang menggunakan sistem jajar legowo dan tegel adalah sebanyak 3 dan 4 orang.

Luas lahan merupakan variabel yang berperan penting dalam produksi padi, semakin banyak luas lahan yang dimiliki oleh petani maka semakin besar peluang untuk memperoleh hasil produksi yang relatif besar. Rata-rata luas lahan garapan petani kedua sistem adalah seluas $1 \mathrm{Ha}$.

Pendapatan Usahatani Padi Sawah yang Menggunakan Sistem Tanam Jajar Legowo dengan Sistem Tegel 
Jurnal Media Agribisnis Vol. 3 No. 1 Tahun 2018 Hal 21 - 29

Media Komunikasi Hasil Penelitian Bidang Ilmu Agribisnis ISSN print 2587-7027

ISSN online 2541-6898

\begin{tabular}{|c|c|c|c|c|c|}
\hline \multirow[t]{2}{*}{ No } & \multirow[t]{2}{*}{ Uraian } & \multicolumn{2}{|c|}{ Sistem Jajar Legowo } & \multicolumn{2}{|c|}{ Sistem Tegel } \\
\hline & & (Rp/Ha/MT) & $\begin{array}{c}\text { Persentase } \\
(\%)\end{array}$ & (Rp/Ha/MT) & $\begin{array}{c}\text { Persentase } \\
(\%)\end{array}$ \\
\hline \multirow[t]{6}{*}{1} & Biaya Tetap & 121.999 & 1,10 & 117.910 & 1,39 \\
\hline & - Parang & 12.288 & 0,11 & 12.086 & 0,14 \\
\hline & - Hand Sprayer & 27.604 & 0,25 & 28.2 & 0,33 \\
\hline & - Sabit & 17.8 & 0,16 & 14.1 & 0,17 \\
\hline & - Arco & 56.180 & 0,51 & 57.08 & 0,67 \\
\hline & - Cangkul & 8.041 & 0,07 & 6.349 & 0,07 \\
\hline \multirow[t]{8}{*}{2} & $\begin{array}{l}\text { Biaya Tidak } \\
\text { Tetap }\end{array}$ & 10.931 .667 & 98,90 & 8.386 .250 & 98,61 \\
\hline & - Bibit & 250.000 & 2,26 & $350 .($ & 4,11 \\
\hline & - Pupuk Kon & 1.000 . & 9,05 & 1.000 & 11,76 \\
\hline & - Pupuk Kin & 675.000 & 6,11 & 675.0 & 7,93 \\
\hline & - Festisida & 220.000 & 1,99 & 220.000 & 2,59 \\
\hline & $\begin{array}{l}\text { - Upah Tenaga } \\
\text { Kerja }\end{array}$ & 8.786 .667 & 79,49 & 6.086 .250 & 71,57 \\
\hline & - Bensin & 0 & 0 & 55.000 & 0,65 \\
\hline & Jumlah & 3.666 & 100 & 8.504 .160 & 100 \\
\hline
\end{tabular}

Sumber : Data Primer yang diolah, 2017

Berdasarkan Tabel 2, terlihat bahwa biaya produksi pada usahatani dengan sistem jajar legowo (Rp.11.053.666/Ha/MT) lebih besar dari sistem tegel (Rp.8.504.160/Ha/MT). Setelah total biaya diketahui baru kita mencari besarnya penerimaan. Penerimaan usahatani padi adalah nilai yang diterima dari penjualan padi sebagaimana terlihat pada Tabel 3 berikut:

Tabel 3. Rata-rata Jumlah Penerimaan Petani Pada Usahatani Padi

\begin{tabular}{rllrr}
\hline \multirow{2}{*}{ No } & \multirow{2}{*}{ Uraian } & \multirow{2}{*}{ Satuan } & \multicolumn{2}{c}{ Jumlah } \\
\cline { 4 - 5 } & & & Jajar Legowo & \multicolumn{1}{c}{ Tegel } \\
\hline 1 & Produksi & $\mathrm{Kg} / \mathrm{Ha} / \mathrm{MT}$ & 5.475 & 3.381 \\
2 & Harga & $\mathrm{Rp} / \mathrm{Kg}$ & 4.500 & 4.500 \\
3 & Penerimaan & $\mathrm{Rp} / \mathrm{Ha} / \mathrm{MT}$ & 24.637 .500 & 15.215 .625 \\
\hline
\end{tabular}

Sumber : Data Primer yang diolah, 2017

Tabel 3, menunjukkan bahwa rata-rata penerimaan usahatani padi dengan sistem tanam jajar legowo (Rp.24.637.500/Ha/MT) juga lebih besar dari sistem tanam tegel (Rp.15.215.625/Ha/MT), sehingga pendapatannya adalah sebagaimana terlihat pada Tabel 4 yang menunjukkan lebih besarnya pendapatan petani dengan sistem jajar legowo (Rp.13.583.834/Ha/MT) dibandingkan dengan sistem tegel (Rp.6.711.465/Ha/MT). 
Jurnal Media Agribisnis Vol. 3 No. 1 Tahun 2018 Hal 21 - 29

Media Komunikasi Hasil Penelitian Bidang Ilmu Agribisnis

ISSN print 2587-7027

ISSN online 2541-6898

\begin{tabular}{llccr}
\hline \multicolumn{3}{l}{ Tabel 4. } & Rata-rata Pendapatan Petani Pada Usahatani Padi Sawah \\
\cline { 3 - 5 } No & \multicolumn{1}{c}{ Uraian } & Satuan & \multicolumn{2}{c}{ Jumlah } \\
\cline { 3 - 5 } & & & Jajar Legowo & \multicolumn{1}{c}{ Tegel } \\
\hline 1 & Penerimaan & $\mathrm{Rp} / \mathrm{Ha} / \mathrm{MT}$ & 24.637 .500 & 15.215 .625 \\
2 & Biaya Produksi & $\mathrm{Rp} / \mathrm{Ha} / \mathrm{MT}$ & 11.053 .667 & 8.504 .160 \\
3 & Pendapatan Usahatani & $\mathrm{Rp} / \mathrm{Ha} / \mathrm{MT}$ & 13.583 .834 & 6.711 .465 \\
\hline
\end{tabular}

Sumber : Data Primer yang diolah, 2017

\section{RC Ratio}

R/C Ratio untuk usahatani padi dengan sistem jajar legowo adalah 2,23 dan untuk usahatani padi dengan sistem tanam tegel adalah 1,79 artinya kedua sistem tanam sama-sama layak untuk dilanjutkan.

\section{Perbedaan Pendapatan dan RC Ratio}

Berdasarkan uji statistik dua rata-rata pendapatan usahatani padi dengan sistem jajar legowo dengan tegel terdapat perbedaan yaitu dilihat dari nilai $Z_{\text {hitung }}(34,92) \geq$ $Z_{\text {tabel }}(1,690)$ pada $\alpha=5 \%$ maka Ho ditolak, maka menunjukkan terdapat perbedaan pendapatan usahatani padi antara sistem tanam jajar legowo dengan sistem tegel. Begitupula dengan $\mathrm{R} / \mathrm{C}$ ratio menunjukkan adanya perbedaan yang nyata berdasarkan nilai $Z_{\text {hitung }}(31,43) \geq Z_{\text {tabel }}(1,690)$.

Tabel 5. Perbandingan Pendapatan dan RC Ratio Usahatani Padi

\begin{tabular}{llrr}
\hline \multirow{2}{*}{ No } & & \multicolumn{2}{c}{ Sistem Usahatani Padi } \\
\cline { 3 - 4 } & & Jajar Legowo & \multicolumn{1}{c}{ Tegel } \\
\hline 1 & Produksi (Kg/Ha/MT) & 5.475 & 3.381 \\
2 & Harga (Rp/Kg) & 4.500 & 4.500 \\
3 & Penerimaan (Rp/Ha/MT) & 24.637 .500 & 15.215 .625 \\
4 & Biaya Produksi (Rp/Ha/MT) & 11.053 .666 & 8.504 .160 \\
5 & Pendapatan (Rp/Ha/MT) & 13.583 .834 & 6.711 .465 \\
6 & RC Ratio & 2,23 & 1,79 \\
7 & Z Hitung Pendapatan & 34,92 & \\
8 & Z Hitung R/C Ratio & 31,43 & \\
\hline
\end{tabular}

Sumber : Data Primer yang diolah, 2017

Pendapatan atau dapat juga disebut keuntungan merupakan selisih anatara penerimaan total dengan biaya total. Untuk mengetahui pendapatan perlu diketahui terlebih dahulu total biaya produksi. Biaya usahatani padi petani di dapat dilihat pada Tabel 2. 
Jurnal Media Agribisnis Vol. 3 No. 1 Tahun 2018 Hal 21 - 29

Media Komunikasi Hasil Penelitian Bidang Ilmu Agribisnis

ISSN print 2587-7027

ISSN online 2541-6898

\section{KESIMPULAN} berikut:

Berdasarkan hasil penelitian dan pembahasan dapat ditarik kesimpulan sebagai

1. Rata-rata pendapatan yang diperoleh petani sampel dari usahatani padi sawah yang menggunakan sistem tanam jajar legowo sebesar Rp 13.477.962/Ha/MT. Sedangkan Rata-rata pendapatan yang diperoleh petani sampel dari usahatani padi sawah yang menggunakan sistem tanam tegel sebesar Rp 6.711.465/Ha/MT.

2. R/C Ratio untuk usahatani padi sawah yang menggunakan sistem jajar legowo dengan tegel adalah 2,23 dan 1,79. Artinya usahatani padi sawah yang menggunakan sistem tanam jajar legowo maupun sistem tegel sama-sama menguntungkan dan layak.

3. Terdapat perbedaan yang nyata pada pendapatan dan $\mathrm{R} / \mathrm{C}$ ratio usahatani padi dengan sistem jajar legowo dan sistem tegel di Desa Pudak, Kecamatan Kumpeh Ulu, Kabupaten Muaro Jambi.

\section{DAFTAR PUSTAKA}

Boediono. 1992. Pengantar Ilmu Ekonomi. Seri Sinopsis. BPFE Gajah Mada, Yogyakarta.

BP3K Arang-Arang, 2015.Program Penyuluhan BP3K. Kumpeh Ulu : BP3K ArangArang.

Dinas Pertanian Tanaman Pangan Provinsi Jambi. 2016. Jambi.

Djarwanto. Ps dan Pangestu Subagya. M. B.A 1993 Satatistik Induktif Edisi Keempat. Yogyajkarta.

Faliatra. 2000 Kelayakan Usaha Pembesaran Ikan Patin (Pangasius Sp) Dalam Kolam. Universitas Batanghari. Jambi.

Nasir, Moh. 1988. Metode Peneitian. Ghalia Indonesia. Jakarta.

Samuelson dan Nordhaus. 2003. Ilmu Mikro Ekonomi. Media Global Edukasi. Jakarta.

Soeharjo dan Patong. 1993. Sendi-Sendi Pokok Ilmu Usahatani Penerbit Departemen Ilmu Sosial Ekonomi Pertanian. IPB. Bogor.

Sudarman, A dan Algifari. 2001. Ekonomi Mikro-Makro. BPFE.Yogyakarta.

Winarno, S. 1994. Pengantar Penelitian Ilmiah. Kanisius. Bandung 